\title{
Erratum to: Superselective intraarterial cerebral infusion of cetuximab after osmotic blood/brain barrier disruption for recurrent malignant glioma: phase I study
}

\author{
Shamik Chakraborty ${ }^{1,2}$ - Christopher G. Filippi ${ }^{2} \cdot$ Tamika Wong $^{1} \cdot$ Ashley Ray $^{1}$. \\ Sherese Fralin $^{1}$ - A. John Tsiouris ${ }^{3} \cdot$ Bidyut Praminick $^{2} \cdot$ Alexis Demopoulos $^{1,2}$. \\ Heather J. McCrea ${ }^{3}$ Imithri Bodhinayake ${ }^{1} \cdot$ Rafael Ortiz $^{1,2} \cdot$ David J. Langer $^{1,2}$. \\ John A. Boockvar ${ }^{1,2,4}$
}

Published online: 6 June 2016

(C) Springer Science+Business Media New York 2016

\section{Erratum to: J Neurooncol \\ DOI 10.1007/s11060-016-2099-8}

One author name was incorrect in the initial online publication. It has been updated in the online article to read correctly as Heather J. McCrea.

The online version of the original article can be found under doi:10.1007/s11060-016-2099-8.

John A. Boockvar

jboockvar@nshs.edu

Shamik Chakraborty

chakrabs@gmail.com

1 Lenox Hill Brain Tumor Center, Lenox Hill Hospital, Northwell Health, New York, NY, USA

2 Departments of Neurosurgery, Neurology, Radiology, and Pathology, Hofstra Northwell School of Medicine, Manhasset, NY, USA

3 Departments of Neurosurgery and Radiology, Weill Cornell Medical College of Cornell University, New York, NY, USA

4 Department of Neurological Surgery, Hofstra Northwell School of Medicine, Manhasset, NY, USA 